\title{
Anemia de Diamond Blackfan, un diagnóstico de exclusión
}

\author{
Álvaro Mondragón-Cardona1, aemondragon@utp.edu.co, Álzate-Carvajal Verónica ${ }^{2}$, Vásquez Francisco ${ }^{3}$, Ortiz-Machacón Jahir ${ }^{4}$ \\ Médico residente Medicina interna. Universidad Surcolombiana. Hospital Universitario Hernando Moncaliano Perdomo. Neiva, Huila, Colombia. \\ Médico. Universidad Tecnológica de Pereira \\ Médico. Universidad del Valle, Colombia. \\ Médico Universidad Rafael Núñez Cartagena, Colombia.
}

Fecha de recepción abril 30 de 2016 Fecha de correcciones septiembre 15 de 2016 Fecha de aceptación noviembre 30 de 2016

Fecha de publicación enero 31 de 2017

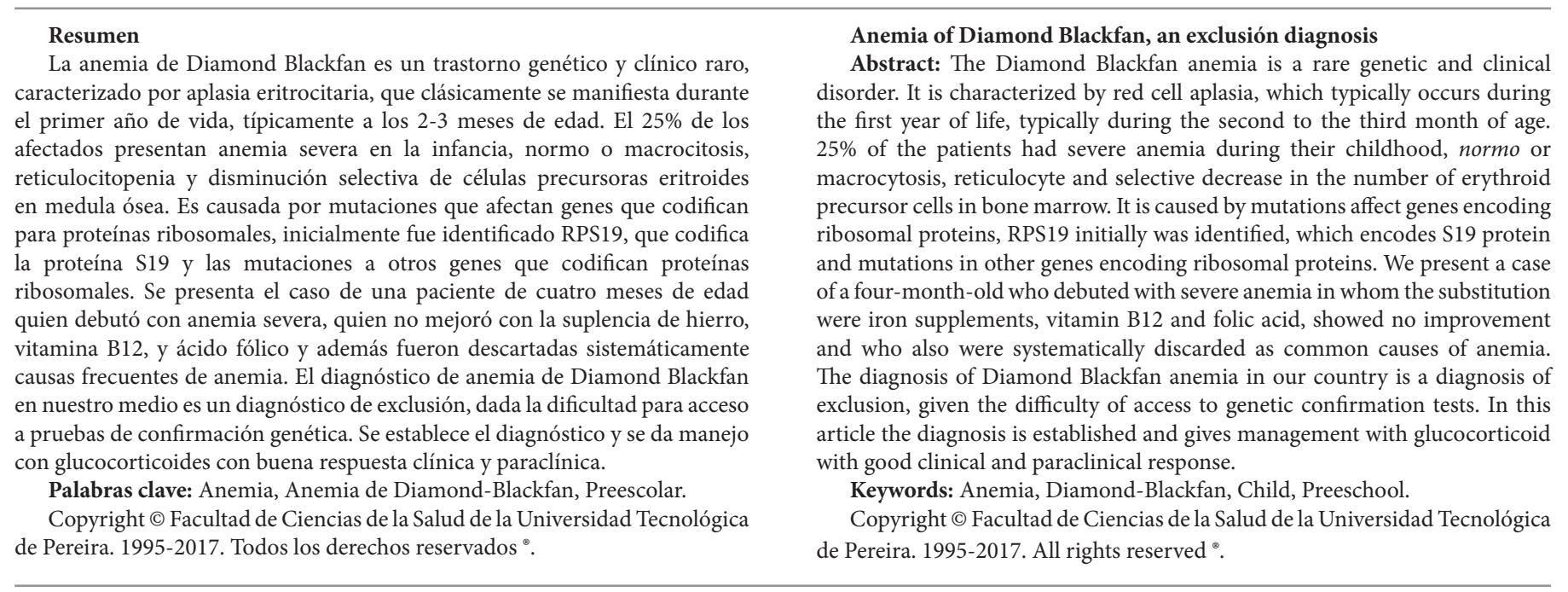

\section{Introducción}

La anemia de Diamond Blackfan (DBA) es un trastorno genético y clínico raro, caracterizado por aplasia eritrocitaria, que clásicamente se manifiesta durante el primer año de vida, típicamente a los 2-3 meses de edad (1). El 25\% de los afectados presentan anemia severa en la infancia, macrocitosis, reticulocitopenia y disminución selectiva de células precursoras eritroides en medula ósea (2), además de aumento en la actividad de Adenosín desaminasa eritrocitaria y elevados niveles de hemoglobina fetal. Así mismo está usualmente asociado a anomalías físicas que se presentan hasta en un 50\% y con un gran rango de severidad, típicamente malformaciones craneofaciales incluyendo hipertelorismo, puente nasal plano, paladar fisurado o arqueado, defectos cardiacos hasta en el 62\%, anomalías en extremidades en el $20 \%$ incluyendo pulgar con tres falanges, también están asociados defectos urogenitales (3), baja talla y un riesgo elevado para desarrollar neoplasias.

La DBA fue reportada por primera vez por Josephs en 1936 y completamente descrita por Diamond y Blackfan en 1938. Los criterios diagnósticos de DBA publicados en 1976 consisten en: presentación de la anemia antes de su primer cumpleaños, conteo de neutrófilos normales o ligeramente disminuidos, plaquetas variables, reticulocitopenia, macrocitosis y celularidad normal de la médula con escasez de precursores de células rojas. Estos criterios, hasta hace poco, seguían siendo la norma aceptada. (6)

Es causada por mutaciones que afectan genes que codifican para proteínas ribosomales, inicialmente fue identificado RPS19, que codifica la proteína S19 (rpS19); y las mutaciones a otros genes que codifican proteínas ribosomales confirman la patología como un trastorno de biogénesis o función ribosomal, ratificado por la demostración de la haploinsuficiencia de RPS14 representado en la anemia macrocítica asociada con el síndrome de 5q- (1), un subtipo de síndrome mielodisplásico. (3)

Aproximadamente el 50\% de los pacientes tienen mutaciones que afectan un único alelo de los genes de proteínas ribosomales S19, L5, L11, o S26. Mutaciones en genes que codifican proteínas ribosomales S7, S24, S17, S10 o L35a son un pequeño porcentaje de casos; todas las mutaciones han sido heterocigotas, lo cual es consistente con el patrón autosómico dominante de la herencia visto comúnmente en la DBA familiar. Las malformaciones craneofaciales están asociadas a mutaciones que afectan RPL5 o RPL11.(1)

La anemia responde hasta en un $70 \%$ de los casos a terapia con esteroides, aproximadamente el $40 \%$ de los afectados dependen de un programa de trasfusión a largo plazo hasta que se encuentra un donante apropiado para un trasplante de células madre hematopoyéticas e inclusive la patología puede resolver después de años de trasfusiones. La terapia de transfusión a menudo tiene que ser combinada con la terapia de quelación del hierro para evitar la hemosiderosis y sus consecuencias deletéreas (6). Según el registro de DBA de Norteamérica la tasa actual de supervivencia es de $75,1 \%$ y $4,8 \%$ a los 40 años de edad; los pacientes que no responden a los esteroides tienen una tasa más baja de supervivencia.(1)

En cuanto a la fisiopatología, existe un defecto que es intrínseco a la célula progenitora de eritrocitos, en la eritropoyesis se observa un deterioro en la fase tardía de las células formadoras de colonias eritroides caracterizada por una disminución en la proliferación y aumento de apoptosis. La demanda extrema centralizada en la biogénesis de ribosomas en pro-eritroblastos, por la combinación de la síntesis de globina y rápida 
proliferación, puede subyacer a la especificidad eritroide del fenotipo DBA. (1)

Aunque son desconocidos sus efectos reales en la fisiopatología de la DBA, la prednisona se ha mantenido como el fármaco de elección para los pacientes DBA desde su uso por primera vez en la década del 50, aproximadamente el $80 \%$ de todos los pacientes responden inicialmente al tratamiento con glucocorticoides, uno de cada dos eventualmente interrumpe el tratamiento debido a la pérdida de respuesta o efectos secundarios graves; estos efectos asociados al tratamiento con glucocorticoides en niños con DBA son comunes e incluyen retraso en el crecimiento, fracturas óseas, infecciones graves, cataratas, hipertensión arterial y diabetes mellitus(3).

\section{Presentación del caso}

Paciente de 4 meses 15 días de edad, sexo femenino, fruto de un embarazo controlado, no complicado, parto a las 40 semanas de gestación, grupo sanguíneo $\mathrm{O} \mathrm{Rh}+$, sin alteraciones, peso al nacer $2.100 \mathrm{~g}$, talla: $47 \mathrm{~cm}$. Sin antecedentes familiares de importancia. Consulta remitida de unidad local por palidez de dos meses de evolución que no mejora a pesar del suministro de sulfato ferroso y ácido fólico, en control de crecimiento y desarrollo. Al examen físico se encuentra palidez extrema en piel y mucosas, peso 6400 $\mathrm{g}$, resto de examen físico dentro de límites normales. Hemograma de ingreso que evidencia: Hemoglobina 5,1 gr/ dL, glóbulos blancos: $3800 / \mathrm{mm} 3$, Polimorfo nucleares: 13,5 \%, Linfocitos: 79 \%, Plaquetas: 293.000/ mm3, Volumen Corpuscular Medio: 97, Concentración de Hemoglobina Corpuscular Media: 31,9; ferritina $758 \mathrm{ng} / \mathrm{mL}$ (referencia 244-278). Se realiza transfusión de $120 \mathrm{cc}$ de concentrado globular, con hemograma post- transfusional que mostraba Hemoglobina 9,1 gr/ dL, recuento de glóbulos blancos: 4600/mm3, Plaquetas: 287.000/ mm3, Volumen Corpuscular Medio: 88, Hemoglobina Corpuscular Media: 32,7, Reticulocitos: 1\%. Fueron realizadas ferritina, transferrina, indice de saturación de transferrina, serología para VIH, niveles de vitamina B12, V.D.R.L, todos dentro de los límites normales.

La paciente es transfundida en múltiples ocasiones por anemia persistente, sin lograr estabilidad en hemoglobina. Se solicita gota gruesa, lactato deshidrogenasa, fosfatasa alcalina y prueba de coombs directa, todas con resultados dentro del rango normal. Se inicia ácido fólico $1 \mathrm{mg}$ / día vía oral en única dosis, hierro elemental $3 \mathrm{cc}$ vía oral cada 8 horas. Se ordena aspirado de medula ósea que mostró disminución de eritroblastos, con escasos elementos eritroides, con presencia de escasos pro-eritroblastos; serie mieloide, megacariocítica y linfoide, sin alteraciones. Se realiza diagnóstico de anemia de Diamond Blackfan, se inicia manejo médico con prednisolona oral 2 $\mathrm{mg} / \mathrm{kg} /$ día, con evolución satisfactoria.

\section{Discusión}

Una paciente pediátrica que presenta anemia durante las primeras 12 semanas, con presencia de normocitosis y reticulocitopenia sin otros hallazgos en el cuadro hemático y otros paraclínicos, que persiste a pesar de transfusiones y manejo con micronutrientes, sugiere la presencia de una anemia hipoproliferativa $(1,2)$. Usualmente estos hallazgos sumados a valores bajos de neutrófilos, presencia de conteo de plaquetas variable, aspirado de médula ósea con disminución en los precursores de glóbulos rojos sugieren la presencia de Anemia de Diamond Blackfan (DBA) (3), aunado a la no mejoría posterior a suplementos de micronutrientes y múltiples transfusiones sanguíneas con presencia de anemia severa (4).

La DBA es un desorden genético poco usual caracterizado por hematopoyesis inadecuada acompañado en el 30\% de los casos con anomalías congénitas (8), oculares, del cuello, del pulgar, tracto urogenital, corazón y cráneo-faciales. Algunos casos presentan baja estatura, retraso de crecimiento y dificultades en el aprendizaje, como consecuencia de mutaciones en RPL11 y RPL5 (6). En este orden de ideas, cabe aclarar que se han identificado mutaciones en proteínas ribosomales RPS24, RPS17, RPL5, RPL11, y RPL35a, sin embargo estas no suelen ser comunes. El 25\% de los genes de los pacientes presentan una mutación en el locus del gen RPS19 chromosome19q13.2. (6). Aproximadamente el $50 \%$ de personas con DBA tienen una única mutación en un gen que codifica una proteína ribosómica, lo que posiciona la DBA como un trastorno de la biogénesis y/o la función del ribosoma (9).

Su forma de presentación, puede variar desde una anemia fetal severa con requerimientos transfusionales, hasta anemia persistente que puede alcanzar los 6 años de edad. La mayoría de casos, presentan un patrón de herencia autosómico recesivo; con una tasa de herencia hasta del 10\% (7).

Un estudio retrospectivo realizado en Corea antes del año 2000, evidenció una relación hombre:mujer en pacientes con DBA, de 1,67:1 (35 varones, 21 mujeres). Entre los pacientes diagnosticados después de esta fecha, la razón hombre-mujer fue de 1,62:1 (21 varones, 13 mujeres), donde sólo 3 casos $(5,4 \%)$ revelaron una historia familiar (7), dato consecuente con la historia familiar de la paciente, sin embargo, se resalta la predilección por el género masculino.

Su forma de presentación clínica típica de anemia hipoplásica congénita, a menudo con palidez como el único síntoma inicial, con hallazgos usuales en laboratorios, que incluyen bajos niveles de hemoglobina, volumen corpuscular medio elevado (MCV) o dentro de rangos de normalidad, y reticulocitopenia. El examen de médula ósea revela un hecho aislado de hipoplasia eritroide en la médula normo-celular. Aunque aún no es validado estadísticamente, los pacientes con DBA también parecen tener un mayor riesgo de leucemia mieloide aguda (LMA) y tumores, por ejemplo, sarcomas osteogénicos (10).

En el caso presentado no se encontró historia familiar alguna de anemias, esperada en el 10\% de los casos. La presencia de anomalías congénitas relacionadas con DBA fue descartada, cuyo porcentaje de presentación está entre el 30-50\% de individuos. (5)

En nuestro medio, el hallazgo de DBA constituye un diagnóstico de exclusión, al cual se llega luego de descartar causas de anemia en los primeros meses de la vida, tales como déficit de vitamina B12, ácido fólico o hierro, talasemias, esferocitosis hereditarias u otras anemias hemolíticas autoinmunes y dada la ausencia en nuestro medio, de pruebas diagnósticas para alteraciones genéticas específicas de la DBA, se asume con los hallazgos clínicos de esta paciente, sumado al extendido de sangre periférica sin alteraciones sugestivas de otras entidades y el aspirado de medula ósea con hipocelularidad de la línea eritroide, que se trata de un caso de DBA.

Es importante aclarar que en nuestro medio no hay reportes suficientes, que permitan realizar eficaz y certeramente el diagnóstico de estos pacientes, con el fin de establecer planes de tratamiento y prevención de complicaciones, que garanticen la calidad de vida de estos pacientes.

Finalmente debe tenerse en cuenta esta entidad diagnóstica, ante la presencia temprana de anemia y la buena respuesta a la terapia con glucocorticoides.

\section{Conflictos de interés}

Los autores declaran no tener conflictos de interés.

\section{Referencias}

1. Lipton J and Ellis S. DiamondBlackfan Anemia: Diagnosis, Treatment and Molecular Pathogenesis. HematolOncolClin North Am. 2009 April ; 23(2): 261-282. doi:10.1016/j.hoc.2009.01.004.

2. Vlachos A, Muir E. How I treat Diamond-Blackfan anemia. Blood 2010;116(19):3715-3723

3. JANUS J, MOERSCHEL S. Evaluation of Anemia in Children.Am Fam Physician.2010;81(12):1462-1471. 
4. Lee A. Transfusion-Dependent Anaemia of Undetermined Origin: A Distinctive Syndrome in Paediatric Medical Tourism. Ann AcadMedSingapore 2012;305-8.

5. Narla A, Vlachos A,Nathan A. DiamondBlackfan Anemia Treatment: Past, Present, and Future. SeminHematol. 2011 April; 48(2): 117-123. doi:10.1053/j.seminhematol.2011.01.004.

6. John Solomon, Rugmini Kamalammal, Godfred Antony Menezes, Mohamed Yaseen Sait, Harita Lohith, Revathy Ramalingam, A CASE OF DIAMOND BLACKFAN ANEMIA (DBA) WITH MUTATION IN RIBOSOMAL PROTEIN S19.Journal of Clinical and Diagnostic Research [serial online]2014 01[cited:2014 Apr 22] 1179 - 180 Available from : http://www.jcdr.net//back_issues.asp

7. Kim SK, Ahn HS, Back HJ, Cho B, Choi EJ, Chung NG, Hwang $\mathrm{PH}$, Jeoung DC, Kang HJ, Kim H, Ko KN, Koo HH, Kook H, Lee KC, Lim HJ, Lim YT, Lyu CJ, Park JE, Park KD, Park SK, Ryu $\mathrm{KH}$, Seo JJ, Shin HY, Sung KW, Yoo ES. Clinical and hematologic manifestations in patients with Diamond Blackfan anemia in Korea. THE KOREAN JOURNAL OF HEMATOLOGY 2012 Jun;47(10):131-135.

8. Campagnoli MF, Ramenghi U, Armiraglio M, Quarello P, Garelli E, Carando A, et al. RPS19 mutations in patients with DiamondBlackfan anemia. Hum Mutat. 2008; Jul; 29(7):911-20.

9. Gazda HT, Grabowska A, Mérida-Long LB, et al. Ribosomal protein S24 gene is mutated in Diamond-Blackfan anemia. Am J Hum Genet 2006; 79:1110-8.

10. Flygare, J., Karlsson, S,. (2007). Diamond-Blackfan anemia: erythropoiesis lost in translation. Bloodjournal. Vol 109, NUMBER 8. http://bloodjournal.hematologylibrary.org 